\title{
Elastografia Acoustic Radiation Force Impulse (ARFI) do tendão flexor digital superficial de equinos
}

Nara Saraiva Bernardi, Michelle Lopes Avante, Ana Paula Rodrigues Simões, Ricardo Andres Ramirez Uscategui, Kamila Gravena, Vinicius Athaydes Canello, Daniela Junqueira de Queiroz, Karina Calciolari, Marcus Antonio Rossi Feliciano, José Corrêa de Lacerda Neto

Universidade Estadual Paulista (UNESP), Jaboticabal, SP, Brasil

*Autor correspondente

e-mail: nara.sb@gmail.com

\section{Resumo}

A elastografia ARFI (Acoustic Radiation Force Impulse) é uma técnica de imagem por ultrassom capaz de avaliar qualitativa e quantitativamente a rigidez tecidual, tendo potencial uso na avaliação das estruturas musculotendíneas. Não existe até o momento aplicação dessa técnica aos tendões e ligamentos de equinos. Sendo assim, objetivou-se com este estudo avaliar a rigidez dos tendões flexores digitais superficiais (TFDS) em equinos hígidos por meio da elastografia ARFI, determinando os padrões quantitativos (velocidade de cisalhamento) ainda não descritos para a espécie em questão. Utilizou-se 24 animais, dos quais se avaliaram ambos os membros torácicos. Após a realização de exames prévios e verificada a ausência de afecções locomotoras, estes foram submetidos ao exame ultrassonográfico convencional e elastografia (método ARFI quantitativo) dos tendões flexores digitais superficiais dos membros torácicos, em diferentes regiões anatômicas. Optou-se realizar as avaliações elastográficas com os animais em posição quadrupedal e os membros apoiados no solo. Para estudo ultrassonográfico, a região metacarpiana deve ser dividida em sete zonas, tomando como base a distância entre o carpo e a articulação metacarpofalângica. Neste estudo foram avaliadas as seis zonas (1A, 1B, 2A, 2B, 3A e 3B) no corte transversal e, subsequentemente, para avaliação com o transdutor em posição longitudinal, o membro foi dividido em três regiões (proximal, média e distal). O delineamento experimental foi inteiramente casualizado e utilizou-se nível de significância de 5\% para todos os testes realizados. Ao elastograma, os TFDSs apresentaram-se homogêneos e rígidos, de coloração avermelhada e não deformáveis. A velocidade de cisalhamento do TFDS não diferiu entre as regiões nos cortes transversais (1A: 7,8 \pm 0,5 m/s; 1B: 7,8 $\pm 0,4 \mathrm{~m} / \mathrm{s} ; 2 \mathrm{~A}: 7,9 \pm 0,5 \mathrm{~m} / \mathrm{s} ; 2 \mathrm{~B}: 7,8 \pm 0,4 \mathrm{~m} / \mathrm{s} ; 3 \mathrm{~A}: 7,9 \pm 0,5 \mathrm{~m} / \mathrm{s}$; 3B: 7,7 $\pm 0,6 \mathrm{~m} / \mathrm{s}$ ). Para os cortes longitudinais, a região proximal do TFDS apresentou maior rigidez do que a região distal (Prox: 7,95 \pm 0,49 m/s; Média: 7,77 $\pm 0,45 \mathrm{~m} / \mathrm{s}$; Distal: 7,72 \pm 0,54 m/s). Também não foram encontradas diferenças entre os membros (esquerdo ou direito). A elastografia ARFI demonstrou-se como 
método apropriado para avaliar o TFDS dos membros torácicos de equinos. Os exames foram realizados com praticidade e alta reprodutibilidade, e possibilitou a determinação de características qualiquantitativas da rigidez tecidual do TFDS. O TFDS mostrou-se homogeneamente rígido nos cortes transversais, porém mais rígido na região proximal quando avaliado em corte longitudinal; dados semelhantes são encontrados quando se avalia a ecogenicidade do TFDS. A técnica foi realizada com sucesso e os resultados obtidos foram alcançados sem dificuldades. A potencial relevância deste trabalho se deve a sua futura aplicação no diagnóstico e acompanhamento das lesões tendíneas. Conclui-se que a elastografia ARFI é uma técnica de imagem simples e não invasiva, que demonstrou ser aplicável e reprodutível para avaliação dos tendões flexores digitais superficiais dos membros torácicos de equinos saudáveis, tendo potencial para ser uma importante ferramenta futura no diagnóstico precoce de lesões tendíneas.

Palavras-chave: Cavalos. Ultrassonografia. Tendinite. 